\title{
Effects of different text difficulty levels on Iranian EFL learners' foreign language Reading motivation and Reading comprehension
}

\author{
Alireza Niazifar and Goodarz Shakibaei*
}

* Correspondence: gshakibaei@ yahoo.com

Department of English, Faculty of Humanities, Ahvaz Branch, Islamic Azad University, Ahvaz, Iran

\begin{abstract}
This study investigated the effects of different text difficulty levels on Iranian EFL learners' foreign language reading motivation and reading comprehension. To fulfil this objective, 40 Iranian participants were selected among 50 students based on the results of Interchange Placement Test (Richards et al, Placement and Evaluation Package Interchange Third Edition/Passages Second Edition with Audio CDs, 2008). The pre-intermediate selected participants were then randomly divided into two equal groups; " $\mathrm{i}+1$ " group $(n=20)$ and "i-1" group $(n=20)$. Afterwards, the researchers measured the participants' English reading comprehension by administering a researchers-made reading comprehension pre-test. Moreover, Motivation for Reading Questionnaire was also conducted. After the participants were all pre-tested, the treatment was practiced on the both groups. The participants in " $\mathrm{i}$ +1 " group received reading passages beyond the current level, on the other hand, the "i-1" group received those reading passages which were below their current level. After the instruction which lasted about 3 months, a modified version of reading comprehension pre-test was administered to the both groups as posttest and finally the data were analyzed by using paired and independent samples t-tests. Moreover, Students' answers to the questionnaire was also analyzed. The obtained results indicated that there was a significant difference between the post-tests of " $\mathrm{i}+$ 1 " and " $\mathrm{i}-1$ " groups. The findings indicated that the " $\mathrm{i}+1$ " group significantly outperformed the " $i-1$ " group $(p<.05)$ on the post-test. Furthermore, the results revealed that the ' $i+1$ ' materials could help Iranian EFL learners increase their reading English motivation. This study has implications for teaching and learning reading comprehension.
\end{abstract}

Keywords: Comprehensible input, Extensive reading, Foreign language reading motivation, Reading comprehension, Text difficulty level

\section{Introduction}

Reading abilities and motivation towards reading among youth have undergone substantial changes as more and more youth rely on the Internet for searching and exchanging information. Hastily browsing through Internet texts is a more predominate type of reading than engaging themselves into an in-depth processing of the written information among these young people (Chiang, 2015). Nevertheless, in-depth processing of the written text

(c) The Author(s). 2019 Open Access This article is distributed under the terms of the Creative Commons Attribution 4.0 International License (http://creativecommons.org/licenses/by/4.0/), which permits unrestricted use, distribution, and reproduction in any medium, provided you give appropriate credit to the original author(s) and the source, provide a link to the Creative Commons license, and indicate if changes were made. 
with sound comprehension is paramount in further developing their analytical and critical thinking skills. Therefore, in spite of the change in the preferred reading mode among young people, reading teachers and researchers are in constant quest of reading activities to cultivate students' positive reading attitudes and subsequently enhance their reading comprehension. To this end, extensive reading (ER) has been identified as one of the most efficacious strategies. ER refers to reading large quantities of materials for pleasure on a frequent and regular basis. Reading materials can range from short stories and novels, newspaper and magazine articles to professional reading (Hedge, 2000).

Extensive reading is widely performed in language classrooms because it is instrumental in motivating students to read and reach higher language proficiency (Day \& Bamford, 1998; Krashen, 2004). In addition, ESL teachers (Hafiz \& Tudor, 1989) have also employed the idea of ER in their language courses and have examined its influences on language learning. A growing number of educators in the EFL context (Iwahori, 2008; Takase, 2007) carried out ER in their language classrooms and investigated its potential effects. The results from this line of inquiry indicate that ER contributes substantially to general language proficiency (Iwahori, 2008; Jackson, 2005), reading comprehension (Takase, 2007), vocabulary (Pigada \& Schmitt, 2006), writing skills (Hafiz \& Tudor, 1989), reading fluency (Iwahori, 2008; Takase, 2007) and grammar (Pigada \& Schmitt, 2006). Moreover, researchers found that ER enhanced learners' reading motivation and reading habits (Chua, 2008).

Many studies have reported the definitive influence of ER, and yet, this approach is still not widely adopted in EFL classrooms. Studies have pointed out several hindrances in implementing ER programmes, such as choosing the texts with optimal difficulty level, sustaining students' interest in reading for a longer period, promoting positive motivation towards reading and appropriating supplementary reading schemes (Urquhart \& Weir, 1998).

The most broadly utilized idea for clarifying the fracture or accomplishment of FL students is motivation. As a key factor in tailing anything in our lives (Gardner, 2001-as cited in Kato, Yasumoto \& Van Aacken, 2007), motivation also plays an important role in language acquisition. It gives a wellspring of vitality that is in charge of why students choose to endeavor to learn another language and to what extent they will proceed with it (Brewster \& Fager, 2000).

One of the sources to provide language input for EFL learners is through ER (Day \& Bamford, 1998). As stated by Krashen (1982), the input to which students are subjected to ought to be a little past their present level of competence, ' $i+1$ ', in which ' $i$ ' refers to the current language ability of learner, whereas ' 1 ' refers to the input that is slightly beyond the learners' current language ability. On the other hand, Day and Bamford (1998) offered a different model on the difficulty level of the input. According to this model, ER is beneficial if it provides language learners with input which is somewhat below their current level of competence (i.e., ' $i$ - 1'). This way language learners can quickly build up their reading confidence, reading fluency and build sight words and high-frequency words (Bahmani \& Farvardin, 2017).

However, a review of the literature uncovers that there is little research on the impacts of these two viewpoints (i.e., ' $i+1$ ' and ' $i-1$ ') on EFL learners' reading comprehension and FLRM. To fill in the existing gap, the current investigation plans to reveal insight into this issue by investigating how ER through ' $i+1$ ' and ' $i$ - 1' materials may influence EFL learners' reading comprehension and foreign language reading motivation. 


\section{Objectives and significance of the study}

This study was administered to help Iranian EFL learners develop their reading comprehension through different text difficulty levels. Therefore, this study followed two objectives. Firstly, it examined the differences between and within the ' $i+1$ ' and the ' $i-1$ ' groups' reading comprehension after three-month participation in extensive reading. In fact, the researchers tried to check if the level and the amount of input students received could have any effect on improving Iranian EFL learners' reading comprehension. Secondly, it checked the differences between and within the ' $i+1$ ' and the ' $i$ - 1 ' groups' foreign language reading motivation after three-month participation in extensive reading. In the second purpose, the researchers aimed to investigate whether presenting input with various levels (i.e., ' $i+1$ ' and the ' $i-1$ ') affect participants reading motivation.

Firstly, this study is significant since its final findings can foster students' motivation and develop their reading comprehension skill through using different text difficulty levels. Moreover, Teachers can take benefit of the ' $i+1$ ' or the ' $i-1$ ' in ER as a supplementary activity in English courses. Secondly, this study may help students understand and comprehend texts and study materials more effectively, and help them provide better answers when taking reading comprehension tests. Eventually, readers who understand the materials well will have the ability to express the ideas that they understand on paper. The results of this study will be beneficial for administrators who make program level decisions in the way that helps them to choose more appropriate passages as the content of the course books. It will also be useful for the teachers and students; teachers will teach specific features of text types to increase their students' comprehending of the texts and finally the students' reading comprehension will improve.

\section{Research questions and null hypotheses}

This study attempted to answer the following questions:

RQ1: Are there any significant differences between and within the ' $i+1$ ' and the ' $i$ 1 ' groups' reading comprehension after three-month participation in extensive reading? If so, which group has higher reading comprehension in English?

RQ2: Are there any significant differences between and within the ' $i+1$ ' and the ' $i$ 1 ' groups' foreign language reading motivation after three-month participation in extensive reading? If so, which group has higher motivation towards reading in English?

Based on the research questions the following null hypotheses are formulated:

H0 1: There aren't any significant differences between and within the ' $i+1$ ' and the ' $i$ - 1' groups' reading comprehension after three-month participation in extensive reading.

H0 2: There aren't any significant differences between and within the ' $i+1$ ' and the ' $i$ - 1' groups' foreign language reading motivation after three-month participation in extensive reading.

\section{Review of the literature}

\section{Theoretical background}

Reading comprehension

Researchers have defined reading comprehension as "a basic piece of the diverse exchange of systems engaged with L2 reading" (Brantmeier, 2003, p. 52). For many 
students, reading is considered as the useful skill that they can use inside and outside the classroom. It is also the skill that can retain the longest time. Allen and Valette (1999) indicated that "reading is more than just assigning foreign language sounds to the written words" (p. 249). It requires the comprehension of what is written. Miller (2008) defined "Reading comprehension as the ability to understand or to get meaning from any type of written materials. It is the reason for reading and the critical component of all content learning" (p. 8).

Moreover, Papalia (2004) said that reading comprehension by and large utilization and all the more particularly in reference to training and psychology has generally the same meaning as understanding the massage of the text. Grellet (1981) assured that "reading comprehension is understanding composed content means eliciting the required data from it as productively as possible" (p. 3). Reading comprehension isn't sufficient to comprehend the substance of the content however more point by point data is essential too.

Wood (2005) confirmed reading involves getting meaning from the written words. Wood declared that reading comprehension as the ability to take lexical information (i.e., semantic information at the word level) and derive sentences and discourse interpretations but reading on graphic based on formation arriving through the eye. Webster's Collegiate Dictionary defined reading comprehension as "the valence of mind to appreciate and understand the meaning communicated by the text."

Reading comprehension among language learners may be different from each other. Related to this, Brantmeier (2003) said that processing the texts similarly or differently, students may have non-identical interpretation of the texts. It means that, language learners may process the text in similar ways but comprehend differently, or process the texts in a diverse way but understand similarly. Day and Park (2005) guaranteed that there are six sorts of reading comprehension which are useful for the language students to become intelligent readers (p. 62). The first is "literal comprehension". It "alludes to a comprehension of the direct importance of the content, for example, actualities, vocabulary, dates, times, and locations" (p. 62). Direct answers are needed for reading questions of this comprehension.

According to Day, literal comprehension might be useful for instructors to know whether students comprehended the essential importance of the content or not. The second sort of the reading comprehension is "rearrangement" in which "learners must utilize data from different parts of the content and consolidate them for additional understanding" (Day \& Park, 2005, p. 62). Reading comprehension items of this type can make language learners to read the text generally. "Inference" is the third sort of the reading comprehension. Day \& Park claim that "an inference involves students combining their literal understanding of the text with their own knowledge and intuitions" (Day \& Park, 2005, p. 63). Another type of the comprehension, according to Day, is "prediction". Students are assumed to guess the final events and occurrences of the text. The fifth sort of perusing understanding is "evaluation". It "requires the student to give a worldwide or thorough judgment about some part of the content; ... keeping in mind the end goal to answer this sort of question, students must utilize both an exacting comprehension of the content and their insight into the content's point and related issues" (Day \& Park, 2005, p. 64). The 6th sort of the perception is "personal response" (Day \& Park, 2005, p. 64). The appropriate responses depend on the subject and demonstrate exacting comprehension of the content. 
It is obvious that background knowledge has a vital part in content handling. Foundation information encourages the language students to focus on the contribution amid reading, have a rich text analysis and comprehension, and also better memory performance (Ellis, 2001). Pulido (2004) mentioned that "knowledge emerges in the course of reading as the reader constructs a text base primarily via bottom up processing, or decoding, of the textual input" (p. 476).

Pulido (2004) proposed that significance of the content winds up coordinated into the reader's worldwide learning, framing a lucid mental portrayal of what the content is about. Therefore, the knowledge is "generated via activation patterns inaugurated by the textual data and the advanced upgrading of formerly established relationships in the text". And the action of the stored information from text in working memory acts as a "signal in an associative manner to all the information stored in long-term memory" (p. 476). Therefore, background knowledge can be activated as an answer to signaling mechanism and has an impact on the construction of meaning representations (Pulido, 2004). The quality of text base has an influence on the role of background knowledge. This quality is influenced by the learners' content handling productivity, for example, the utilization of explanatory information structures, and sentence parsing (Pulido, 2004). In an investigation about the vocabulary attained through reading administered by Pulido (2004), it was found that the amount of vocabulary gain can be increased when participants read narratives which have familiar topics for learners.

In interactive theories of reading, second language reading is considered as a cognitive process in which learners by using their background knowledge, and interaction with information, construct the meaning (Pulido, 2004). Stanovich (1992) claimed that the processes in reading are not restricted to interactive process, but also compensatory process in a way that when a component of processing is absent, other components of processing can be compensated for.

\section{Extensive reading}

Not only language arts teachers but also ESL/EFL teachers regard ER as a crucial element for language development and widely incorporate ER into their classroom practice. In addition to the term 'extensive reading', Krashen (2004) called it 'Pleasure Reading' or 'Free Voluntary Reading' to convey the same idea defined by Davis (1995). 'An extensive reading program is a complementary class library scheme, attached to an English course, in which pupils are given the time, encouragement, and materials to read pleasurably, at their own level, as many books as they can, without the pressures of testing or marks' (Davis, 1995, p. 329). Extensive reading (ER) is a kind of extended reading activity that addresses this limitation in class time (Chiang, 2015). ER exposes the student to sufficient reading material "with the attention for the most part on the importance of what is being read [rather] than on the language" (Carrell \& Carson, 1997, pp. 49-50).

Davis' definition and Day and Bamford's delineation suggest that taking part in ER provides learners with ample language input, the opportunities to choose reading texts, and the chance to experience pleasure. Unlike intensive reading, which emphasizes decoding skills and focuses on comprehension of the text, ER centers on readers' prolonged engagement in reading activities. One of the most frequently cited theoretical underpinnings for ER is Krashen's Input Hypothesis, which states that sufficient exposure to comprehensible input is indispensable for language learners to acquire the 
language. Comprehensible input denotes the kind of input that is a little bit beyond the learner's current language level and is usually symbolized with the expression, ' $i+1$ ' (Mitchell \& Myles, 2004). ' $i$ ' refers to the current language ability of the learner, whereas ' 1 ' indicates the input that is slightly challenging for learners' current language ability. Krashen asserts that i+ 1 is the prerequisite condition for language acquisition to take place (Krashen, 2002). This theory stresses the importance of input as well as the comprehensibility of the input.

However, Day and Bamford (1998) hold a different perspective on the optimal difficulty level of the input. As far as ER is concerned, they believe it is beneficial to provide language learners with input that is slightly below the learners' current language level. In other words, instead of ' $\mathrm{i}+1$ ', Day and Bamford (1998) see ' $\mathrm{i}-1$ ' as the learners' 'comfort zone' where language learners can quickly build up their reading confidence and reading fluency. They also pointed out that reading books with ease at the beginning helps language learners build sight words and high-frequency vocabulary (Chiang, 2015).

Comparing Krashen's ' $i+1$ ' hypothesis with Day and Bamford's 'i 1' statement, two principles can be derived. First, language input plays a crucial role in language learning and providing language learners with ample access to input is important. Secondly, not only the quantity of input matters but also the quality is important. The quality of input mainly concerns how comprehensible the input is to the intended learners. Nevertheless, the dispute between ' $\mathrm{i}+1$ ' and ' $\mathrm{i}-1$ ' remains unsolved. That is the rationale behind this study.

\section{Reading motivation}

What is reading motivation? This is a question many teachers and researchers have thought about for many years. Everyone knows that motivation is something that gives fulfillment to someone. This means that a person wants to do something to better him/herself. As discussed by Protacio (2012), reading problems occur partly due to the fact that people are not motivated to read in the first place. Protacio explains that, motivation occurs when "students develop an interest in and form a bond with a topic that lasts beyond the short term" (p. 251).

Guthrie and Wigfield (2000, p.405) propose that "reading motivation is the individual's personal objectives, values, and beliefs regarding the topics, processes, and outcomes of reading". According to this definition, one would come to two main conclusions: The first is that reading motivation is made up of the putting together of different aspects of motivation in a complex way. The second is the kind of agency individuals have over it since they can manage, organize and direct their motivation to read according to their beliefs, values and goals (Wigfield \& Tonks, 2004).

In a research treating the dimensions of reading motivation, Baker and Wigfield (1999) confirm the view about the multidimensionality of reading motivation . Paris and Carpenter (2004) argue that this feature in reading motivation has to do with the nature of motivation as "a difficult psychological construct to define and measure, and [consequently] there is no single way to view or assess children's motivation for reading" (p.78).

Day and Bamford (1998) give a broad view explaining motivation for reading in second/foreign language. They propose cognitive models to explain motivation where this concept is made up of "two equal components -expectations and value" (p.27). These models claim that individuals would undertake activities about which they expect to perform well, and would avoid any activity in which they have lesser expectations of success. These expectations about different degrees of success in tasks are determined 
by the extent to which individuals value the task (Day \& Bamford, 1998). Furthermore, the model presented by Day and Bamford (1998) is also to witness on the multi-faceted nature of reading motivation, despite the fact that it gives only two components -expectancy and value- (Mori, 2002).

As far as reading is concerned, Day and Bamford (1998, p.27) posit that "unless students have a reasonable expectation that they will be able to read a book with understanding, they will most likely not begin the undertaking". The second component of motivation for reading, which is value, needs also to be fulfilled. In a perfect situation, students would consider a reading activity essentially important for them "in learning to read and as a source of pleasure and information" (Day \& Bamford, 1998, p.28).

According to Day and Bamford (1998), students of a second language decide to read in the second language depending on the two key concepts (expectancy and value). The expectancy component relates to reading materials students are exposed to in terms of the amount and type of interest the material may stimulate, the linguistic structure and the language used in the reading material, attractiveness as established both by the interest of the text and by its linguistic structure, the availability of the reading material and whether students have easy access to the material. Paris and Carpenter (2004) agree with this opinion about the role of the reading material. They explain that "motivation to read is affected by both the content and structure of text" (p.69). Students' proficiency level in the target language as part of their ability in reading in the target language also plays a role in building their expectancy. Value is related to attitudes of students toward the target language because it emerges from the beliefs, they hold about it. In addition to that, values students have, are the fruit of constraints exerted by their society, native culture, with a great influence from family and peers. Paris and Carpenter (2004) share this same view as they believe that, to some extent, motivation to read lies within individuals.

Day and Bamford (1998, p.28) claim that variables concerning the reading material and attitude towards reading in the target language have stronger effect on motivation than other variables do. In the same respect of what Day and Bamford (1998) present as components of reading motivation, Paris and Carpenter (2004) assert that reading motivation emerges from the complex combination and interaction of children's experience with reading and their abilities, their aim behind undertaking a reading task, the features of the reading material, and the social backing context of the reading task.

Mori (2002) hypothesizes that, despite the differences, reading motivation in the second/foreign language is greatly similar to reading motivation in one's first language; thus, reading motivation in second/foreign language "would be a multidimensional construct, and, to a certain degree, independent of general motivational constructs" (p.95). The fact that reading motivation is not automatically assimilated to general motivation results from the assumption that "students' motivation may be, to a certain extent, domain-specific [...] students may be, for example, motivated to speak or listen, but not to read in English" (Mori, 2002, p.92). In other words, students may show diverse degrees of motivation for some activities in the second/foreign language and not others, but not necessarily all. 


\section{Taxonomy of text difficulty}

Krashen's Input Hypothesis asserts that an indispensable condition for language acquisition to happen is that "The acquirer understand[s] input language that encompasses structure 'a bit beyond' his or her present level of competence. If an acquirer is at stage i, the input he or she understands should contain $i+1$ " (Krashen, 1981, p. 100).

According to this hypothesis, Krashen (1985) elucidated that the $i+1$ stage indicates some linguistic components in the text that the reader has not yet mastered and that are beyond the reader's competence. However, the scope of the input corresponding to $i+1$ is still not vivid. Several questions can be raised, such as what degree of increase in difficulty is just far enough, and whether input of $i+1$ is suitable for English learners of different English abilities. Other applicable inquiries incorporate what different levels of input can be included and whether different levels of input may add to enhancing FL/SL students' reading.

In this study, text difficulty will be specified by linguistic components. This study adopts readers which are graded based on vocabulary and sentence structure. The linguistic elements of the input considered in the present study were vocabulary and grmmar which were also investigated in Day and Bamford's (2002) study. Following Samuel's (1994) terms, three levels of text difficulty were applied in this study: (a) level i- 1 represents vocabulary and syntactic structures below the learner's English linguistic competence; (b) level i represents vocabulary and syntactic structures at the learner's current English linguistic competence; and (c) level $\mathrm{i}+1$ represents vocabulary and syntactic structures beyond the learner's English linguistic competence.

\section{Experimental backgrounds}

Related to this study, Lin (2012) investigated which level of graded reader was most appropriate for Chinese-speaking learners of different English capacities and whether there were critical contrasts in reading comprehension and vocabulary learning when distinctive English proficiency (EP) bunches read writings of fluctuating trouble levels. Eight-two senior secondary school learners in Taiwan were separated into low, medium and high EP groups (LEP, MEP, and HEP). They read evaluated readers at Level 2, Level 3, and Level 4 after class and finished understanding and vocabulary tests, and a text difficulty poll. The outcomes appear, first, that the most reasonable reviewed readers for LEP, MEP, and HEP groups were found. Second, there were critical contrasts among the three EP groups in the comprehension and vocabulary test scores of these readers. Third, there was a significant correlation between reading comprehension and vocabulary obtaining when each group read the content suitable for its level of phonetic competency.

Chiang (2015) researched the impacts of different text difficulty on L2 reading perceptions and reading comprehension. To give the ideal test to L2 reading, comprehensible input hypothesis hypothesizes that selecting text somewhat harder than the student's present level will improve reading perception. Fifty-four freshman from one college in central Taiwan were arbitrarily separated into two groups. Students in the ' $\mathrm{i}-1$ ' group were given level 3 and level 4 Oxford Graded Readers while students in the ' $i+1$ ' group were provided with level 5 and level 6. Quantitative data were collected through the English Placement Exam and the Reading Attitudes Survey. Findings from the pretest and posttest of the Reading Attitudes Survey propose that the $\mathrm{i}-1$ group has gained significantly in reading attitudes, whereas no difference 
in reading attitude was identified with the $\mathrm{i}+1$ group. Results also indicate that diverse difficulty levels of reading text did not significantly influence participants' reading comprehension. It is vital to note that Chiang's study should be repeated in different context that probably reach different results.

Recently, Bahmani and Farvardin (2017) examined the impacts of different text difficulty levels on foreign language reading anxiety (FLRA) and reading comprehension of English as a Foreign Language (EFL) learners. To this end, 50 elementary EFL learners were selected from two intact classes $(n=25$ each). Each class was assigned to a text difficulty level (i.e., ' $i+1$ ' and ' $i-1$ ') in which the participants experienced extensive reading at different levels of difficulty for two semesters. A reading comprehension test and the Foreign Language Reading Anxiety Scale (FLRAS) were run before and after the treatment. The outcomes indicated that both text difficulty levels significantly enhanced the participants' reading comprehension. The findings also showed that, at the end of the study, the ' $i+1$ ' group's FLRA increased, while that of the ' $i$ - 1 ' group decreased. Regarding text-difficulty levels, many other participants' aspects should be taken in account. That is, motivation, age, proficiency, and gender should be checked in this regard. Therefore, in this study reading motivation was considered.

\section{Method}

\section{Participants}

Forty pre-intermediate EFL students from a private language Institute in Ahvaz were selected among 70 volunteers through administrating an Interchange Placement Test (Richards, Lesley, Hansen, Sandy \& Zukowski, 2008). Upon the administration of this test, 40 participants whose test scores were one standard deviation below or above the mean score were selected as the homogeneous group of pre-intermediate EFL learners. They were all male students and their age range was 16 to18. The selected participants were non-randomly divided into two groups namely " $\mathrm{i}+1$ " and " $\mathrm{i}-1$ " groups, each group contains 20 participants. The students were all the same regarding their educational background, age and sex. All of them enrolled for this English class during the autumn semester of 2015, a period of 12 weeks. The material which was taught in the class, was "Interchange Level 2". Based on Cambridge English Language Teaching (CELT) classification, "Interchange Level 2 " is appropriate for A2 - B1 level. It is worth mentioning that Interchange Placement Test (2008) was run to the participants to get sure about their proficiency level. The " $i+1$ " group received input which was beyond their current level, while the "i-1" group received input which was beneath their current level. It should be mentioned that every week, twenty minutes of the class time was considered for narrating the stories participants have read.

\section{Instrumentations}

\section{Interchange placement test}

The first instrument which was utilized in the present study to homogenize the participants was the Interchange Placement Test, developed by Richards et al. (2008). Interchange Placement Test consists of 70 multiple-choice items: 20 listening items, 20 reading items and 30 items related to language use in order to select the pre-intermediate level of EFL learners. The reliability value of this test was computed through Cronbach's Alpha formula as $(\alpha=0.781)$. There is general agreement that +.78 or above indicates 
appropriate instrument reliability. According to the scoring guidelines of the test, the scores between 18 and 23 belonged to the pre-intermediate level. The participants had 60 min to answer the questions. The reason why the researchers of the study decided to utilize IPT as the students' measure of proficiency was due to the fact that the test is a standard test of proficiency, and its validity and reliability were assumed to be satisfactory.

\section{ACTIVE skills for Reading}

The second instrument used in this study was a reading book named ACTIVE Skills for Reading series published by Heinle ELT. It is a breathtaking five-level reading series that improves students' reading perception and vocabulary abilities. It was written by famous expert Neil J. Anderson, the new edition of this best-selling series uses an ACTIVE approach to help learners become more confident, independent-and active-readers. ACTIVE Reading A = Actuate former Knowledge $\mathrm{C}=$ Cultivate Vocabulary $\mathrm{T}=$ Think about Meaning $\mathrm{I}=$ = Increase Reading Fluency V = Verify Strategies E = Evaluate progression. It was accessible to the students in the library of the institute.

\section{Reading comprehension test}

Eight passages and their comprehension questions were extracted from Active Skills for Reading, Book 1 by Anderson (2008), and used in this study. The eight passages were chosen based on the familiarity of the topic to the students. Then 40 multiple-choice questions were prepared based on these 8 passages. Multiple-choice questions were applied to assess the students' reading comprehension; students could be assessed objectively for it was likely that they understood the text without being able to express it in L2. At the end of the experiment, to find about the possible effects of the oral pre-reading tasks on the students' reading comprehension, a posttest was administered. It should be mentioned that the posttest was at the same level to pretest but the items were different. The allotted time was $70 \mathrm{~min}$ and each item received one point.

The mentioned test received some reliability and validity measures. After construction, it was examined by ten experts for its face and content validity. That is, to get sure about the Content Validity Index (CVI) of the test items, ten teachers who also taught English for more than 5 years read through the tests and made some changes regarding the clarity, simplicity and the representativeness of items. Subsequently, the test was modified and then piloted on a similar group in another institute whose course book and level were the same. The reliability of the pre-test and post-test was computed through the application of Cronbach Alpha formula and values of 0.896 and 0.793 were obtained respectively.

\section{The motivation for Reading questionnaire (MRQ)}

Another instrument used in the current study was a modified version of Motivation for Reading Questionnaire (MRQ) developed by Guthrie and Wigfield (1997), and a modified version of the same questionnaire adopted by Mori (2002). In their final version of the original MRQ, Guthrie and Wigfield (2000) proposed eleven components as basis for the questionnaire, with fifty-three items. These components were Reading Efficacy, with 3 items; Challenge, 5 items; Curiosity, 6 items; Reading Involvement, 6 items; Importance, 2 
items; Recognition, 5 items; Grades, 4 items; Social, 7 items; Competition, 6 items; Compliance, 5 items; and Reading Work Avoidance, 4 items.

The final version of the questionnaire which was used, consisted of 30-item five-point Likert scale questionnaire intended to investigate the reading motivation dimensions. The scale was made up of five propositions: 1 for 'I strongly agree', 2 for 'I agree', 3 for 'I don't know', 4 for 'I disagree', and 5 for 'I strongly disagree'. The questionnaire included eight dimensions with each consisting of a number of statements illustrated as follows: Challenge, 5 statements; Compliance, 5 statements; Curiosity, 4 statements; Grades, 3 statements; Importance of Reading, 2 statements; Reading Efficacy, 2 statements; Reading Involvement, 5 statements; Reading Work Avoidance, 4 statements.

\section{Data collection procedure}

At first 40 male students out of 70 from a private Language Institute in Ahvaz were selected through administering an Interchange Placement Test (Richards et al., 2008). The selected participants were divided into two groups: " $i+1$ " group $(n=20)$ and " $i-1$ " group $(n=20)$. Both groups were under the instruction in 20 sessions, during 10 weeks, twice a week and $70 \mathrm{~min}$ per session. Next, both groups took a teacher-made test as a reading comprehension pretest which was developed by the researchers based on the course book content and was checked against validity and reliability measures. Moreover, Motivation for Reading Questionnaire was also conducted.

Afterwards, the " $i+1$ " group received reading passages above the current level, on the other hand, the "i-1" group received those reading passages which were below their current level. The reading passages were selected from ACTIVE Skills for Reading series and the interchange books series. These books were available in the library and bookstore of the language institute. Moreover, it was proposed that if students could not find the book of their interest, they were able find them from other libraries and bookstores outside.

At the beginning of each week, the participants were informed how many pages they required to read. Moreover, at the end of each week, $20 \mathrm{~min}$ of the class was considered for participants to report. They were also given time to talk around various sections of the passages or stories, their ideas about the major theme of the reading passages, and even gave some remarks related to the passages. Moreover, some activities like question and answer (Q\&A) was also used. Q\&A consisted of giving participants some questions about the text and students were encouraged to share their answers and to build ideas of each other's responses. Finally, after about 3 months and at the end of the study, a posttest was administered to both groups as the posttest of the study. The procedure was similar to the pretest. Moreover, they answered the MR questionnaire. The reliability of pre-test and posttest was calculated by using Cronbach Alpha formula and values of 0.896 and 0.793 were obtained respectively. To get sure about the validity of the test, opinions of five experts were obtained.

\section{Data analysis}

In order to analyze the data, Statistical Package for Social Science (SPSS) software version 25 was used. Firstly, Kolmogorov-Smirnov (K-S) test was used in order to check the normality of the data. Secondly, descriptive statistics including means and standard deviation were calculated. Independent and Paired Samples t-test were conducted to compare the means of the ' $i$ +1 ' and ' $i$ - 1'group. Moreover, Students' answers to the questionnaire was also analyzed. 


\section{Results}

\section{Analyzing pre and post-tests}

In order to analyze the gathered data, the SPSS software, version 25 software was used.

Table 1 shows that the statistics of scores is normal as the results obtained from using SPSS 25. In this case, the parametric statistics like independent samples t-test and paired samples t-test can be used to get the final results.

In Table 2, the descriptive statistics of both groups is presented in both pretest and posttest. The $\mathrm{i}+1$ group's mean score in pretest is 11.80 and the $\mathrm{i}-1$ group's mean score in pretest is 11.65. This means that the both groups are somehow similar in pretest since they are homogeneous at the beginning of the treatment. Moreover, the above table reveals the descriptive statistics of both groups on the post-test. The $\mathrm{i}+1$ group's mean score in posttest is 12.65 and the $\mathrm{i}-1$ group's mean score in posttest is 15.30 . An independent samples t-test is needed to show the difference between the pretest and post-tests of both groups (Table 3).

In Table 3, an independent samples t-test was used to show the scores of both groups on the pre-test. Since the Sig (.300) is greater than 0.05 , the difference between the groups is not significant at $(p<0.05)$. In fact, they performed the same on the pre-test. Moreover, Table 3 indicates that the difference between the both groups is significant at $(p<0.05)$. In fact, the $\mathrm{i}+1$ group had better performance than the $\mathrm{i}-1$ group on the post-test (Table 4).

Based on the descriptive statistics in the above table, the mean scores of $i+1$ group on the pre and post-tests are 11.80 and 15.30, respectively, and the mean scores of $\mathrm{i}-1$ group on the pre and post-tests are 11.65 and 12.65, respectively (Table 5).

In the above table, a paired samples t-test is used to compare the pre and post-tests of each group. The difference between the pre-test and post-test the $i+1$ group is significant since Sig (.000) is less than 0.05, similarly, the difference between the pre-test and post-test of the $\mathrm{i}-1$ group is significant since Sig (.004) is less than 0.05 .

\section{Analyzing questionnaire}

Table 6 shows the descriptive statistics of the questionnaire before and after the treatment. The mean scores of both groups before the treatment seem very equal; the mean of the $\mathrm{i}-1$ group is 81.40 and the mean of $\mathrm{i}+1$ group is 81.80 . It implies that both groups had the same motivation before receiving the treatment. Moreover, Table 6

Table 1 One-Sample Kolmogorov-Smirnov Test (Groups' Pre and Post-tests)

\begin{tabular}{llllll}
\hline & & Pre i +1 & Post i +1 & Pre i-1 & Post i-1 \\
\hline N & & 20 & 20 & 20 & 20 \\
& Mean & 11.8000 & 15.3000 & 11.6500 & 12.6500 \\
& Std. Deviation & .41039 & 1.45458 & .48936 & 1.63111 \\
Most Extreme Differences & Absolute & .487 & .332 & .413 & .355 \\
& Positive & .313 & .332 & .258 & .355 \\
& Negative & -.487 & -.186 & -.413 & -.225 \\
Kolmogorov-Smirnov Z & & 2.178 & 1.483 & 1.846 & 1.587 \\
Asymp. Sig. (2-tailed) & & .081 & .055 & .052 & .063 \\
\hline
\end{tabular}

${ }^{\mathrm{a}}$ Test distribution is Normal

b. Calculated from data 
Table 2 Descriptive Statistics (Pre-test and Posttest of Both Groups)

\begin{tabular}{llllll}
\hline Tests Groups & & $\mathrm{N}$ & Mean & Std. Deviation & Std. Error Mean \\
\hline Pretest & $\mathrm{i}+1$ & 20 & 11.80 & .41 & .09 \\
& $\mathrm{i}-1$ & 20 & 11.65 & .48 & .10 \\
\multirow{3}{*}{ Posttest } & $\mathrm{i}+1$ & 20 & 15.30 & 1.45 & .32 \\
& $\mathrm{i}-1$ & 20 & 12.65 & 1.63 & .36 \\
\hline
\end{tabular}

indicates the descriptive statistics of the questionnaire after the treatment. The mean scores of both groups after the treatment seem very different; the mean of the $\mathrm{i}-1$ group is 82.15 and the mean of $\mathrm{i}+1$ group is 128.35 . It means that the $\mathrm{i}+1$ group had better scores after the treatment.

In Table 7, an independent samples t-test was used to show the scores of both groups on the questionnaire. Since the Sig $(.836)$ is greater than 0.05 , the difference between the groups is not significant at $(p<0.05)$. Furthermore, in Table 7 , an independent samples t-test was used to show the scores of both groups on the questionnaire. Since the Sig (.00) is less than 0.05 , the difference between the groups is significant at $(\mathrm{p}<0.05)$. In fact, the $\mathrm{i}+1$ group improved their motivation after the treatment.

\section{Discussion}

In this part, the researchers discussed the results of the study and answered the questions raised in chapter one. So, the questions of the present research are answered below.

RQ1: Are there any significant differences between and within the ' $\mathrm{i}+1$ ' and the ' $\mathrm{i}$ 1 ' groups' reading comprehension after three-month participation in extensive reading? If so, which group has higher reading comprehension in English?

Based on the results of the present study, both ' $i+1$ ' and ' $i-1$ ' groups got the same scores on the pre-test. But on the post-test the experimental (' $i+1$ ') group outperformed the control (' $\mathrm{i}-1$ ') group. Therefore, the first null hypothesis of the study "There are not any significant differences between and within the ' $i+1$ ' and the ' $i-1$ ' groups' reading comprehension after three-month participation in extensive reading" is rejected.

Students of the experimental group had improvement on the post-test thanks to the treatment they had received. The researchers found that the classes were more

Table 3 Independent Samples t-test (Pre-test and Posttest of Both Groups)

\begin{tabular}{|c|c|c|c|c|c|c|c|c|c|c|}
\hline & & \multicolumn{2}{|c|}{$\begin{array}{l}\text { Levene's } \\
\text { Test for } \\
\text { Equality } \\
\text { of } \\
\text { Variances }\end{array}$} & \multicolumn{7}{|c|}{ t-test for Equality of Means } \\
\hline & & \multirow[t]{2}{*}{$\mathrm{F}$} & \multirow[t]{2}{*}{ Sig. } & \multirow[t]{2}{*}{$\mathrm{t}$} & \multirow[t]{2}{*}{ Df } & \multirow[t]{2}{*}{$\begin{array}{l}\text { Sig. } \\
(2- \\
\text { tailed) }\end{array}$} & \multirow[t]{2}{*}{$\begin{array}{l}\text { Mean } \\
\text { Difference }\end{array}$} & \multirow[t]{2}{*}{$\begin{array}{l}\text { Std. Error } \\
\text { Difference }\end{array}$} & \multicolumn{2}{|c|}{$\begin{array}{l}95 \% \\
\text { Confidence } \\
\text { Interval of the } \\
\text { Difference }\end{array}$} \\
\hline & & & & & & & & & Lower & Upper \\
\hline \multirow[t]{2}{*}{ Pretest } & Equal variances assumed & 4.43 & .042 & 1.05 & 38 & .300 & .150 & .14 & -.13 & .43 \\
\hline & Equal variances not assumed & & & 1.05 & 36.88 & .300 & .150 & .14 & -.139 & .439 \\
\hline \multirow[t]{2}{*}{ Posttest } & Equal variances assumed & 1.04 & .313 & 5.42 & 38 & .000 & 2.65 & .48 & 1.66 & 3.63 \\
\hline & Equal variances not assumed & & & 5.42 & 37.51 & .000 & 2.65 & .48 & 1.66 & 3.63 \\
\hline
\end{tabular}


Table 4 Paired Samples Statistics (Pre and Post-tests of Both Group)

\begin{tabular}{llllll}
\hline & & Mean & N & Std. Deviation & Std. Error Mean \\
\hline Pair 1 & Pre i + 1 & 11.8000 & 20 & .41039 & .09177 \\
& Post i + 1 & 15.3000 & 20 & 1.45458 & .32525 \\
Pair 2 & Pre i-1 & 11.6500 & 20 & .48936 & .10942 \\
& Post i-1 & 12.6500 & 20 & 1.63111 & .36473 \\
\hline
\end{tabular}

challenging and the students were more involved in learning to understand the reading texts. The improvement of the students can be attributed to the ' $\mathrm{i}+1$ ' reading texts as Krashen (1982) states input which is slightly beyond the current level of competence of the language learner can be conducive to learning. If $i$ is the language learner's current level of competence in the foreign language, then $i+1$ is the next immediate step along the development continuum. Therefore, if the goal is to assist the language learner progress in their task, it is essential to provide the student/learner with comprehensible input $[i+1]$.

The researchers observed that the students were more motivated to read and understand the texts that were more difficult for them, they seemed curious to know the meaning of unfamiliar words and phrases, consequently, they asked the researchers to provide the meaning of unknown words, phrases, and sentences, and this attempt led to their success in reading comprehension.

This study is supported by Bahmani and Farvardin (2017) who discovered the effectiveness of different text difficulty levels on FLRA and reading comprehension of EFL learners. The final findings uncovered that both text difficulty levels significantly enhanced the participants' reading comprehension. The findings also showed that, at the end of the study, the ' $i+1$ ' group's FLRA increased, while that of the ' $i$ - 1 ' group decreased.

This study revealed that both ' $\mathrm{i}+1$ ' and ' $\mathrm{i}-1$ ' groups had better performances on their post-tests compared to their pre-tests but, ' $\mathrm{i}+1$ ' group outperformed the ' $\mathrm{i}-1$ ' groups on the post-test. So, it is crucially urgent to take into account the difficulty levels of the texts while teaching and learning.

RQ2: Are there any significant differences between and within the ' $\mathrm{i}+1$ ' and the ' $\mathrm{i}$ 1 ' groups' foreign language reading motivation after three-month participation in extensive reading? If so, which group has lower motivation towards reading in English?

After analyzing the data, it was revealed that the students in ' $i+1$ ' group were more motivated than the ' $\mathrm{i}-1$ ' group. It means that after the treatment which lasted about three months, it was revealed the ' $i+1$ ' group' motivation towards reading in English was remarkably increased in contrast with the other group (i.e., 'i - 1' group). Consequently, the second null hypothesis of the study "There are not any significant differences between and within the ' $i+1$ ' and the ' $i$ - 1' groups' foreign language reading motivation after three-month participation in extensive reading" is rejected. The results of this study are in contrast with Chiang (2015) who investigated the different text difficulty levels on L2 reading perceptions and reading comprehension. The findings showed that diverse difficulty levels of reading text did not significantly influence participants' reading. 
Table 5 Paired Samples Test (Pre and Post-tests of Both Group)

\begin{tabular}{|c|c|c|c|c|c|c|c|c|}
\hline & \multicolumn{5}{|c|}{ Paired Differences } & \multirow[t]{3}{*}{$\mathrm{t}$} & \multirow[t]{3}{*}{ df } & \multirow{3}{*}{$\begin{array}{l}\text { Sig. } \\
\text { (2- } \\
\text { tailed) }\end{array}$} \\
\hline & \multirow[t]{2}{*}{$\overline{M e a n}$} & \multirow[t]{2}{*}{$\begin{array}{l}\text { Std. } \\
\text { Deviation }\end{array}$} & \multirow{2}{*}{$\begin{array}{l}\text { Std. } \\
\text { Error } \\
\text { Mean }\end{array}$} & \multicolumn{2}{|c|}{$\begin{array}{l}\text { 95\% Confidence Interval of the } \\
\text { Difference }\end{array}$} & & & \\
\hline & & & & Lower & Upper & & & \\
\hline Pair 1 Pre $i+1$ - Post $i+1$ & -3.500 & 1.31789 & .29469 & -4.11679 & -2.88321 & -11.877 & 19 & .000 \\
\hline Pair 2 Pre i-1 - Post i-1 & -1.000 & 1.37649 & .30779 & -1.64422 & -.35578 & -3.249 & 19 & .004 \\
\hline
\end{tabular}

In contrast to the common belief that easy materials may increase the motivation of EFL learners, this study proved that the more difficult materials could increase Iranian EFL learners' motivation towards reading English. It can be claimed that difficult materials have discovery nature, meaning that, students want to discover and understand new things. In addition, students may do not have much more motivation to learn easy and ordinary materials without rich content. These results are in line with previous research (Chiang, 2015; Tanaka, 2007). Constant exposure to the input (i.e., $\mathrm{i}+1$ ) over 3 months seemed to have had a significant effect on developing participants' reading comprehension. It could be possible that consistent exposure to written input facilitated the participants' incidental vocabulary learning (Mikeladze, 2014).

\section{Conclusion}

This research compared the effects of ' $i+1$ ' and ' $i$ - 1' materials on extensive reading of Iranian EFL learners. The findings indicated that both ' $i+1$ ' and ' $i$ - 1' groups had better performances on their post-test in comparing to their pre-tests but there was a significant difference between their post-tests, in fact, the ' $i+1$ ' group outperformed the ' $i$ - 1' group on the post-test. The ' $i+1$ ' materials could help Iranian EFL learners increase their reading English motivation after three-month. It can be concluded that test difficulty levels should be considered in selecting the target reading texts of EFL English books. In addition, it can be concluded that the materials of EFL English textbooks should be one level higher than the current level of the students to motivate and challenge them. This study comes to the conclusion that the input hypothesis of Krashen (1982) "learners progress in their knowledge of the language when they comprehend language input that is slightly more advanced than their current level" is valid.

The other conclusion which can be drawn from this study is the importance of the EFL learners' motivation. The motivation of the students should be increased to learn English language more easily since motivation directs behavior toward particular goals, it will increase students' time on task and is also an important factor affecting their learning and achievement. Motivation enhances cognitive processing. Motivation determines whether a student will pursue a task (even a difficult one) with enthusiasm or a

Table 6 Descriptive Statistics (Questionnaire of Both Groups before and after the Treatment)

\begin{tabular}{llllll}
\hline & groups & N & Mean & Std. Deviation & Std. Error Mean \\
\hline Pretest & i-1 group & 20 & 81.40 & 5.80 & 1.29 \\
& i +1 group & 20 & 81.80 & 6.30 & 1.40 \\
Posttest & i-1 group & 20 & 82.15 & 6.73 & 1.50 \\
& i +1 group & 20 & 128.35 & 16.54 & 3.691 \\
\hline
\end{tabular}




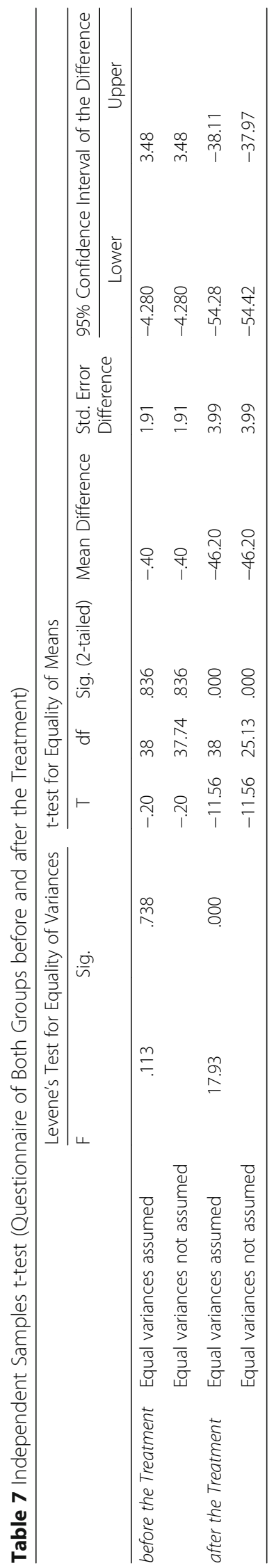


lackluster attitude. So, it is important to recognize aspects that foster internal motivation in English language learning.

This study provides some implications for teachers, learners, and material designers. Teachers can benefit from the ' $i+1$ ' or the ' $i-1$ ' in reading courses as a supplementary activity. This study can make teachers aware to take the text difficulty levels into account when they want to teach reading texts. In addition, the findings can help teachers to motivate their learners through challenging them with more difficult texts. Teachers should try to familiarize their students with innovative teaching strategies such as the one explored in this study- text difficulty levels. Based on the findings of this study, EFL learners can expose themselves to more comprehensible inputs to learn English language more easily. This study showed that comprehension precedes production, so, EFL learners should be subjected to much more comprehensible input. This study underscores the importance of input both for teachers and learners. The findings of the present study can make the material designers aware to incorporate English texts suitable to the students' level of proficiency in EFL English books.

It is crucially important to mention that the results of this study supported the study done by Bahmani and Farvardin (2017). However, there is a main difference. In fact, Bahmani and Farvardin focused more on reading anxiety and they did not pay attention to reading motivation.

\section{Abbreviations \\ EFL: English as a foreign language; ER: Extensive Reading; ESL: English as a Second Language; FL: Foreign Language; FLRA: Foreign Language Reading Anxiety; FLRM: Foreign Language Reading Motivation; i: input; MRQ: Motivation for Reading Questionnaire; Post: Posttest; Pre: Pretest; SL: Second Language}

\section{Acknowledgements}

Not Applicable.

Funding

The study did not receive any funding.

Availability of data and materials

Please contact corresponding author for data requests.

\section{Authors' contributions}

Both authors of the research had more or less equal contributions in the process of conception and design, acquisition of data, and analysis and interpretation of data. They have all been involved in revising the manuscript critically to the same extent. Both take public responsibility for the whole content. Both are equally accountable for all aspects of the work. Both authors read and approved the final manuscript.

Competing interests

The authors declare that they have no competing interests.

\section{Publisher's Note}

Springer Nature remains neutral with regard to jurisdictional claims in published maps and institutional affiliations.

Received: 22 January 2019 Accepted: 30 April 2019

Published online: 22 May 2019

\section{References}

Allen, E., \& Vallette, R. (1999). Classroom techniques: Foreign languages and English as a second language. Cambridge, MA: Harvard University Press.

Bahmani, R., \& Farvardin, M. T. (2017). Effects of different text difficulty levels on EFL learners' foreign language reading anxiety and reading comprehension. Reading in a Foreign Language, 29(2), 185-202.

Baker, L., \& Wigfield, A. (1999). Dimensions of children's motivation for reading and their relations to reading activity and reading achievement. Reading Research Quarterly, 34, 452-477.

Brantmeier, C. (2003). Does gender make a difference? Passage content and comprehension in second language Reading. Reading in a Foreign Language, 15, 1-27.

Brewster, C., \& Fager, J. (2000). Increasing student engagement and motivation: From time-on-task to homework. Northwest Regional Educational Laboratory. Retrieved from http://educationnorthwest.org/webfm_send/452. 
Carrell, P. L., \& Carson, J. G. (1997). Extensive and intensive reading in an EAP setting. English for Specific Purposes, 16(1), 47-60.

Chiang, M. (2015). Effects of varying text difficulty levels on second language (L2) reading attitudes and reading comprehension. Journal of Research in Reading, 39(4), 1-21.

Chua, S. P. (2008). The effects of the sustained silent reading program on cultivating students' habits and attitudes in reading books for leisure. The Clearing House, 81(4), 180-184.

Davis, C. (1995). Extensive reading: An expensive extravagance? ELT Journal, 49(4), 329-335.

Day, R. R., \& Bamford, J. (1998). Extensive reading in the second language classroom. Cambridge: Cambridge University Press.

Day, R. R., \& Bamford, J. (2002). Top ten principles for teaching extensive reading. Reading in a Foreign Language, 14(2), 136-141.

Day, R. R., \& Park, J. (2005). Developing reading comprehension questions. Reading in a Foreign Language, 17(1), 60-73.

Ellis, N. C. (2001). Memory for language. In P. Robinson (Ed.), Cognition and second language instruction (pp. 33-68). New York: Cambridge University Press.

Grellet, F. (1981). Developing Reading skills. Cambridge: Cambridge University Press.

Gardner, R.r. (2001). Language learning motivation: The student, the teacher and the researcher. Key-note address to the Texas Foreign Language Education Conference, University of Texas, Austin.

Guthrie, J. T., \& Wigfield, A. (1997). Relations of children's motivation for reading to the amount and breadth or their reading. Journal of educational psychology, 89(3), 420.

Guthrie, J.T., \& Wigfield, A. (2000). Engagement and motivation in reading. In M.L. Kamil, P.B. Mosenthal, P.D. Pearson, \& R. Barr (Eds.), Handbook of reading research: Volume III (pp. 403-422). New York, NY: Erlbaum.

Hafiz, F. N., \& Tudor, I. (1989). Extensive reading and the development of language skills. ELT Journal, 43(1), 4-13.

Hedge, T. (2000). Teaching and learning in the language classroom. Oxford: Oxford University Press.

Iwahori, Y. (2008). Developing reading fluency: A study of extensive reading in EFL. Reading in a Foreign Language, 20(1), 70-91.

Jackson, K. (2005). Rewarding reading. English Teaching Professional, 39, 15-18.

Kato, F., Yasumoto, S., \& Van Aacken, S. (2007). A comparative study: Motivation of learners of Japanese. Electronic Journal of Foreign Language Teaching, 4(1), 41-57.

Krashen, S. (1981). Second language acquisition and second language learning. Pergamum press, oxford.

Krashen, S. (1982). Principles and practice in second language acquisition. New York: PrenticeHall.

Krashen, S.D. (1985). The input hypothesis: Issues and implications. New York, Longman.

Krashen, S. D. (2002). Explorations in language acquisition and use: The Taipei lectures. Taipei: Crane.

Krashen, S.D. (2004). The power of reading (2nd ed.). Portsmouth, NH: Heinemann.

Lin, L. F. (2012). The impact of text difficulty on EFL learners' reading comprehension and vocabulary learning. I-manager's Journal on English Language Teaching, 2(2), 14-24.

Mikeladze, T. (2014). Extensive reading. Telavi: Telavi Lakob Gogebashvili State University.

Miller, D. (2008). Reading with Meaning Teaching Comprehension in the Primary Graders (pp. 53-157). Portland: Stenhouse.

Mitchell, R., \& Myles, F. (2004). Second language learning theories (2nd ed.). New York: Oxford University Press.

Mori, S. (2002). Redefining motivation to read in a foreign language. Reading in a Foreign Language, 14, 91-110.

Papalia, A. (2004). Titled from Interactive Languages Teaching. Harvest University. Cambridge University Press.

Paris, S. G, \& Carpenter, R. D. (2004). Children's Motivation to Read. In James V. Hoffman \& Diane L. Schallert (Eds.), The Texts in Elementary Classrooms (pp.61-82). Mahwah, New Jersey: Lawrence Erlbaum Associates.

Pigada, M., \& Schmitt, N. (2006). Vocabulary acquisition from extensive reading: A case study. Reading in a Foreign Language, $18,1), 1-1), 28$

Protacio, M. (2012). Reading motivation: A focus on English learners. The Reading Teacher, 66(1), 69-77.

Pulido, D. (2004). The effect of cultural familiarity on incidental vocabulary acquisition through Reading. The Reading Matrix an Online International Journal, 4, 20-53.

Richards, J. C., Lesley, T., Sandy, C., Hansen, C., \& Zukowski, J. (2008). Placement and evaluation package interchange third edition/passages second edition with audio CDs (Vol. 2). Cambridge: Cambridge University Press.

Samuels, S. J. (1994). Toward a theory of automatic information processing in reading, revisited. In R. B. Ruddell, M. R. Ruddell, and H. Singer (Eds.), Theoretical models and processes of reading (4th ed.) (pp. 816-837). Newark, DE: International Reading Association.

Stanovich, K. E. (1992). Speculations on the causes and consequences of individual differences in early reading acquisition. In P. B. Gough, L. C. Ehri, \& R. Treiman (Eds.), Reading acquisition (pp. 307-342). Hillsdale, NJ: Erlbaum.

Takase, A. (2007). Japanese high school students' motivation for extensive L2 Reading. Reading in a Foreign Language, 19(1), 1-18.

Tanaka, H. (2007). Increasing reading input in Japanese high school EFL classrooms: An empirical study exploring the efficacy of ER. The Reading Matrix, 7(1), 115-131.

Urquhart, S. \& Weir, C. (1998). Reading in a second language: Process, product and practice. Harlow, Essex, UK: Pearson Education Limited.

Wigfield, A., \& Tonks, S. (2004). The development of motivation for read- ing and how it is influenced by CORI. In J. T. Guthrie, A. Wigfield, \& K. C. Perencevich (Eds.), Motivating reading comprehension: Concept Oriented Reading Instruction (pp. 249-272). Mahwah, NJ: Erlbaum.

Wood, C. (2005). Beginning readers' use of 'talking books' software can affect their reading strategies. Journal of Research in Reading, 28(2), 170-182. 